\title{
EVALUATION OF ANTIOXIDANT ACTIVITY OF SOME PLANT EXTRACTS AND THEIR EFFECTS ON THE STABILITY OF LIPIDS IN BISCUITS \\ Hefnawy T.H. ${ }^{*}$ and Gehan A. El-Shourbagy ${ }^{\star *}$ \\ Biochemistry Department, Faculty of Agriculture, Zagazig University, 44519, Zagazig, Egypt. \\ "Food Science Department, Faculty of Agriculture, Zagazig University, 44519, Zagazig, Egypt.
}

\begin{abstract}
The aim of this investigation was to study the antioxidant potential of carrot, grape leaves and turmeric powder extracts and its application as natural antioxidants compared with synthetic antioxidants in biscuits processing. Physicochemical properties of biscuit samples were evaluated during processing and storage. Biscuits prepared with grape leaves extract (GLE), carrot extract (CE), and turmeric powder extract (TPE) were well acceptable. Among the antioxidants used, TPE was found to retain only $11.23 \%$ activity wherein GLE had retained $51 \%$ activity after baking, which was comparable to butylated hydroxyanisole (BHA) and better than tertbutylhydroquinone (TBHQ). Based on the result of retention of antioxidant activity during baking and storage, GLE, CE and TPE were found to be suitable for biscuit baking as natural antioxidants wherein the results were comparable with $\mathrm{BHA}$.

Keywords: Biscuits; grape leaves; turmeric powder; carrot; synthetic and natural antioxidants.
\end{abstract}

\section{INTRODUCTION}

Antioxidants have been an indispensable group of food additives, because they effectively retard lipid oxidation in food products, thereby extending the shelf-life without any alteration in sensory and nutritional qualities, Madhavi et al. (1996). The safety of commonly used synthetic antioxidants [butylated hydroxyanisule (BHA), butylated hydroxyl-toluene (BHT), tert-butylhydroquinone (TBHQ) and propylgallate has been questioned due to toxicity, liver damage and carcinogenicity (Ferreira, 2012). Thus, development and use of safer antioxidants in human diet from natural sources are of interest. Several studies demonstrate that a variety of plant species possess bioactive phytochemicals that may be used as a natural antioxidants, Liu \& $\mathrm{Ng}$ (2000) and Yu et al. (2005). Plant extracts have received much attention as sources of biologically active substances including antioxidants, antimutagens and anticarcinogens, Dillard \& German (2000). Extracts obtained from some fruits and vegetables have been reported to be effective antioxidants, Vinson et al. (1998).

Biscuits are of the most popular bakery products due to its ready-toeat, good nutritional quality, availability in different varieties, affordable cost 
and long shelf life. The keeping quality of baked foods such as biscuits is of great economic importance since these products contain fats and oils which are exposed to oxidation during long storage. Oxidation products cause rancidity and deterioration of the sensory properties. Oxidation of fats and oils may be prevented or even delayed by antioxidants, Mildner et al. (2009). Natural aromatic plants and spices have been widely used in many food products such as meat and meat products, dairy as well as bakery products, Park et al. (1994) and Pokorny \& Jan (1991). Bioactive phytochemicals such as $\beta$-carotene, $\alpha$-tocopherol, phytate, ferulic acid and ascorbic acid have been used in various bakery products as antioxidants, Park et al. (1997) and Ranhotra et al. (1995). The spices most commonly used in bakery products are cinnamon, mint, nutmeg, cloves and sesame seeds, Bassiouny et al. (1990). Some studies have reported the use of marjoram, spearmint, peppermint and basil as natural antioxidants in biscuit baking, Bassiouny et al. (1990) and Bajaj et al. (2006). The antioxidant properties of plant extracts have been attributed to their phenol contents of leaves and grape skins, Monagas et al. (2006).

Many wastes generated by agro-industries contain polyphenols with potential application as food antioxidants and preventive agents against some diseases, Li \& Zhong (2004). The grape (Vitis vinifera L, family Vitaceae) leaves have been used to stop bleeding and to treat inflammatory disorder, pain, hepatitis and free radical related disease, Pari \& Suresh (2008). The grape leaves contain a wide range of phenolic compounds including anthocyanins, flavonoids and also organic acids, Fan et al. (2004).

Carrot (Daucus carota L, family Umbelliferae) is one of the most commonly used vegetable in the world. Phytochemical investigations have shown the presence of alkaloids, saponins, mannitol, betulic acid and $\beta$ sitosterol in carrot peels, Sharma et al. (1995) and Tripathi et al. (1996). Carrots are recognized as a good source of $\beta$-carotene $(c a .20 .45 \mathrm{mg} / 100 \mathrm{~g}$ ), which acts as an antioxidant, Chantaro et al. (2008) and Hiranvarachat \& Devahastin (2014). Because of the fact that polyphenols, flavonoids, anthraquinones are known to exhibit antioxidative properties, Dixit \& Kar (2009), which are also present in the carrot, it was thought to explore their antioxidant properties, if any. Shyamala \& Jamuna (2010) studied the composition and antioxidant potential of carrot pulp waste and noted that the $\beta$-carotene content of carrot pulp waste was $3.92 \mathrm{mg} / 100 \mathrm{~g}$, whereas the recommended $\beta$-carotene in a dietary allowance for a typical adult is 4.8 $\mathrm{mg} / 100 \mathrm{~kg}$.

The rhizome of Curcuma longa L, (turmeric) belonging to the family Zingiberaceaeis which is traditionally used in many countries to enhance the food quality, flavor and antioxidant properties, Krishnaswamy (2008) and Liju et al. (2013). Turmeric is one of the most investigated medicinal plants. In recent years, turmeric has received much attention worldwide due to its wide spectrum of pharmacological activities. Curcumin, desmethoxycurcumin and bisdesmethoxycurcumin are the major bioactive compounds in turmeric rhizomes and are called as curcuminoids (CMNs), Anubala et al. (2014). Park et al. (2013) studied the phenolics and flavonoids, as well as activities of radical scavenging (DPPH and ABTS radical scavenging activity) and anti- 
obesity were assessed with cold water (CLC), hot water (CLH), and methanolic (CLM) extracts of turmeric. The results showed that the phenolics of CLC, CLH and CLM were $3.68 \%, 3.94 \%$ and $9.01 \%$, respectively. The turmeric extract had potent cholesteryl ester transfer protein inhibitory ability (up to $23 \%$ inhibition) at a concentration of $10 \mu \mathrm{g} / \mathrm{mL}$ and it inhibited the cellular uptake of oxidized low-density lipoprotein into macrophages, which is the initial step in atherogenesis, Jin et al. (2011).

Therefore, the aim of the present investigation was to study the impact of carrot extract (CE), grape leaves extract (GLE) and turmeric powder extract (TPE), as sources of natural antioxidants, as well as synthetic antioxidants on the processing and physcochemical properties, as well as the stability of lipids in biscuits during storage.

\section{MATERIALS AND METHODS}

\section{Materials:}

Commercially available wheat flour (72\% extraction) was used for biscuits making. The shortening and other food-grade chemicals such as sodium bicarbonate, ammonium bicarbonate, salt, skim milk powder, sugar powder used for baking biscuits were obtained from local markets (Zagazig, Egypt). Fresh grape leaves, turmeric powder and carrot were obtained also from local market. Synthetic antioxidants (BHA and TBHQ) and a-tocopherol were obtained from Sigma (St. Louis, MO, USA).

\section{Analysis and properties of wheat flour:}

The moisture, ash gluten, sodium dodecyl sulfate (SDS) contents and Farinograph analysis in wheat flour were determined according to American Association of Cereal Chemists methods, AACC (2000).

Antioxidant activity of wheat flour, plant extracts as natural antioxidants and synthetic antioxidants (BHA and TBHQ) was determined by the method of Prieto et al. (1999). The antioxidant activity was determined spectrophotometrically by the phosphomolybdenum method, which is based on the reduction of $\mathrm{Mo}(\mathrm{IV})$ to $\mathrm{Mo}(\mathrm{V})$ by the sample analyte and subsequent formation of green phosphate/Mo(V) compounds with a maximum absorption at $695 \mathrm{~nm}$. Antioxidant activity was expressed in terms of micromoles of $\alpha$ tocopherol per gram of sample.

\section{Preparation of plant extracts:}

\section{Carrot extract (CE)}

Fresh tuber roots of carrot $(500 \mathrm{~g})$ were peeled, washed, cut into small pieces and homogenized in a warring blender with 2.5 volumes of distilled water. The extraction was carried out at $25 \pm 2^{\circ} \mathrm{C}$ with constant stirring overnight. The homogenate was then squeezed through cheese cloth and centrifuged at $1200 \mathrm{xg}$ for $10 \mathrm{~min}$ at $4{ }^{\circ} \mathrm{C}$. The supernatant being the CE (yield $21 \%$, w/w) was decanted and kept at $4{ }^{\circ} \mathrm{C}$ until used. The solvent-free extracts were used in the present study.

Grape leaves extract (GLE)

The grape leaves were washed, dried in shade, powdered and extracted by maceration with $70 \%(\mathrm{v} / \mathrm{v})$ ethanol for $72 \mathrm{~h}$ at $25 \pm 2^{\circ} \mathrm{C}$. The extract was 
filtered and then solvent evaporated to dryness under reduced pressure in a rotary evaporator. The residual extract was used for the study.

Turmeric powder extract (TPE)

Turmeric powder $(200 \mathrm{~g})$ were homogenized in a warring blender with 2.5 volumes of distilled water. The extraction was carried out at $25 \pm 2{ }^{\circ} \mathrm{C}$ with constant stirring overnight. The homogenate was centrifuged at $1200 \times \mathrm{g}$ for $10 \mathrm{~min}$ at $4{ }^{\circ} \mathrm{C}$. The supernatant being the TPE (yield $36 \%$, w/w) was decanted and kept at $4^{\circ} \mathrm{C}$ until used. The solvent-free extracts were used in the present study.

Biscuit preparation:

Biscuits were prepared as descried by Sai \& Rao (1999). Sugar $(90 \mathrm{~g})$ and shortening $(60 \mathrm{~g})$ were creamed for $4 \mathrm{~min}$ in a Hobart mixer. Wheat flour (300 g) sieved twice with baking powder $(0.9 \mathrm{~g})$ was added and mixed for $3 \mathrm{~min}$. Different antioxidants were blended with the shortening and the emulsion was mixed with sugar. The specified amount of dough water (50-60 ml), which containing sodium and ammonium bicarbonate $(1.5 \mathrm{~g}$ and $3 \mathrm{~g}$ ), as well as sodium chloride $(3 \mathrm{~g})$ was added gradually to the above cream for 5 min to obtain a homogenous and a slightly firm dough. The dough was sheeted to a thickness of $3.5 \mathrm{~mm}$, cut into circular shapes using $45-\mathrm{mm}$ cutter, placed on an aluminium tray, and baked at $160^{\circ} \mathrm{C}$ for $10 \mathrm{~min}$, then allowed to cool. The biscuits were stored in air-tight containers at $25 \pm 2{ }^{\circ} \mathrm{C}$. for 2 months as storage period.

Biscuits were prepared to provide five treatments. Control treatment was prepared without plant extracts addition. Other treatments were prepared by adding synthetic antioxidant (BHA and TBHQ, 200 ppm) and plant extracts $(1 \%, w / w)$ under study (GLE, CE and TPE).

\section{Physicochemical properties of biscuits:}

Moisture and ash contents of biscuits were determined according to American Association of Cereal Chemists methods, AACC (2000). Biscuits enriched with various extracts were analyzed for physical parameters such as weight, width, thickness, ratio of width to thickness (W/T) and spread factor, Sai \& Rao (1999).

\section{Sensory analysis of biscuits:}

Sensory analysis of biscuits prepared with different extracts at different levels was conducted and various sensory parameters such as color, surface characteristics, crumb color, texture, taste and mouth feel were analyzed, Sai \& Rao (1999). For this test, 10 members semi trained panelists from the staff of Food Science Department, Zagazig University were involved and the mean of 10 values was taken.

\section{Texture measurement of biscuits:}

The breaking strength of biscuits was measured by the triple beam snap (also called three-point break) technique using an Instron Texture Analyzer (Model TAHDi, Stable Microsystems, Godalming, UK) according to the method described by Bajaj et al. (2006). The biscuit sample was rested on two supporting beams spread at a distance of $3 \mathrm{~cm}$., another beam connected to a moving part was brought down to break the biscuits at a crosshead speed at $10 \mathrm{~mm} \mathrm{~min}^{-1}$ and load cell of $10 \mathrm{~kg}$. Care was taken to see that the point of contact was equivalent from both the supporting beams. 
The peak force $(\mathrm{kg})$ at break, representing breaking strength, was recorded and average values were calculated.

Determination of peroxide value (PV):

Peroxide value of biscuits was determined according to the method described in AOAC (1986) at 0,15 and 60 days during storage. The result was expressed as Milli equivalents of $\mathrm{O}_{2} \mathrm{~kg}^{-1}$ of fat.

Statistical analysis:

Student $t$-tests were performed to evaluate the statistical significance of the results. The $P$-levels at 0.05 and below were considered significant, Snedecore and Cochran (1980).

\section{RESULTS AND DISCUSSION}

\section{Characterization of wheat flour and extracts:}

The wheat flour used for biscuit preparation was analyzed for proximate composition. The moisture, ash, SDS sedimentation value, wet gluten and dry gluten contents of the flour were found to be $11.5 \%, 0.61 \%, 38 \mathrm{~mL}$, $30.21 \%$ and $9.27 \%$, respectively. The Farinograph characteristics of wheat flour showed dough development time, stability of dough, water absorption of wheat flour (on 14\% moisture basis) and mixing tolerance index to be 2.5 min, $5 \mathrm{~min}, 56.8 \mathrm{~mL}$ and $120 \mathrm{BU}$, respectively. Results indicated that the quality of wheat flour was medium hard and suitable for biscuit preparation, Sai \& Rao (1999) and Pomrtanz (1988).

The antioxidant activity of wheat flour $(72 \%)$, studied plant extracts and synthetic antioxidants indicated that wheat flour had the lowest antioxidant activity $\left(0.07121 \mu \mathrm{mol} \alpha\right.$-tocopherol $\left.\mathrm{g}^{-1}\right)$. The antioxidant activities of different sources differ in their values Table (1). Among the tested antioxidants, TBHQ was found to possess the highest activity $(P<0.001)$, followed by GLE, TPE and $C E$, respectively. The variation in antioxidant activity could be due to the natural and/or the amount of bioactive compounds present in the different sources used in this study. Obtained results show that TPE and GLE can be used as a good source of natural antioxidants.

Table 1:Antioxidant activities of wheat flour (72\%), different plant extracts and synthetic antioxidants ( $\alpha$-tocopherol $\mathrm{g}^{-1}$ of sample)

\begin{tabular}{|c|c|}
\hline Sample & Antioxidant activity $\left(\mu \mathrm{mol} \mathrm{g}^{-1}\right)$ \\
\hline Wheat flour (72\%) & $0.070 \pm 0.0008$ \\
\hline Carrot extract (CE). & $228.7 \pm 0.47$ \\
\hline Tumeric powder extract (TPE) & $726.0 \pm 0.52$ \\
\hline Grape leaves extract (GLE) & $1115 \pm 0.32$ \\
\hline Butylated hydroxyanisole (BHA) & $371.0 \pm 0.64$ \\
\hline tert-butylhydroquinone (TBHQ) & $1185 \pm 0.53$ \\
\hline
\end{tabular}

Values are mean \pm SD of six replicates ${ }^{*} P<0.001$. 


\section{Physicochemical properties of biscuits:}

The results revealed that antioxidant-enriched biscuits possessed less moisture content than control Table (2). This may be due to more water binding with other ingredients of biscuit formulation in the case of antioxidantenriched biscuits. GLE-enriched biscuits possessed least moisture content $(P<0.01)$. However, TPE-enriched biscuits possessed moisture content nearer to control, but biscuits with synthetic antioxidants (BHA and TBHQ) were found to retain more moisture when compared to natural antioxidants. This shows that synthetic antioxidants interacted differently with the water content of formulation from natural antioxidants (BHA $P<0.001$; TBHQ $P<$ $0.001)$.

Table 2: Influence of various antioxidants on moisture and ash contents (as \% weight basis) of biscuits

\begin{tabular}{|l|c|c|}
\hline \multicolumn{1}{|c|}{ Sample } & Moisture & Ash \\
\hline Biscuit (control) & $4.18 \pm 0.08$ & $1.26 \pm 0.01$ \\
\hline Biscuit + CE & $4.10 \pm 0.19^{\text {NS }}$ & $1.20 \pm 0.01$ \\
\hline Biscuit + TPE & $4.14 \pm 0.01^{\text {NS }}$ & $1.28 \pm 0.01$ \\
\hline Biscuit + GLE & $3.99 \pm 0.09^{*}$ & $1.28 \pm 0.01$ \\
\hline Biscuit + BHA & $4.44 \pm 0.11^{\text {"N }}$ & $1.32 \pm 0.02^{\text {"⿻ }}$ \\
\hline Biscuit + TBHQ & $4.72 \pm 0.12$ & $1.32 \pm 0.01$ \\
\hline
\end{tabular}

${ }^{N 5}$ Not significant; ${ }^{*} P<0.01 ;{ }^{* *} P<0.001$.

Another important parameter is the ash content of biscuits. The present study indicates that the ash content of biscuits with TPE and GLE was nearer to that of the control sample, whereas the ash content of BHA and TBHQ treatments was higher than that of the control. These results are in agreement with Nanditha et al. (2009) and Pomrtanz (1988).

Biscuits with different antioxidants, studied plant extracts and synthetic antioxidants, were evaluated for weight/biscuit, width, thickness, width/thickness $(\mathrm{W} / \mathrm{T})$ ratio and spread factor. The obtained results are shown in Table (3). The weight of control sample was the highest, wherein CEbiscuit was heavier compared to other biscuits with natural antioxidants. Weights of CE and TPE samples were comparable to TBHQ sample. The width of the CE-biscuit was much less. Width of TPE sample was comparable to control sample wherein the width of GLE and CE samples were comparable to BHA and TBHQ samples. The thickness of BHA biscuits was found to be similar to control. However, the thickness of CE sample was greater than control. The thickness of TPE and GLE samples was comparable to TBHQ-treated sample, but less than the control due to shrinkage. It was observed that the addition of TPE, GLE, BHA or TBHQ to biscuits increased the $\mathrm{W} / \mathrm{T}$ ratio due to reduced thickness of the biscuits. On the other hand, addition of CE reduced the $\mathrm{W} / \mathrm{T}$ ratio due to increased thickness and reduced weight. Spread factor of control biscuits was considered $100 \%$. CE sample had a spread factor less than 100 due to low W/T ratio, whereas spread factor of TPE, GLE and TBHQ samples was more than 100. BHA-treated sample was comparable to control in this respect. 
Table 3: Effect of incorporation of antioxidants on physical parameters of biscuits

\begin{tabular}{|l|c|c|c|c|c|}
\hline Biscuit sample & $\begin{array}{c}\text { Weight } \\
\text { (biscuit) }\end{array}$ & $\begin{array}{c}\text { Width } \\
\text { (mm) } \\
\text { (biscuit) }\end{array}$ & $\begin{array}{c}\text { Thickness } \\
\text { (mm) } \\
\text { (biscuit) }\end{array}$ & W/T ratio & $\begin{array}{c}\text { Spread } \\
\text { factor }\end{array}$ \\
\hline Biscuit- control & $9.74 \pm 0.13$ & $57.66 \pm 0.13$ & $6.16 \pm 0.13$ & $9.36 \pm 0.14$ & $100.0 \pm 0.48$ \\
\hline Biscuit + CE & $8.52 \pm 0.11$ & $56.00 \pm 0.15$ & $6.33 \pm 0.13$ & $8.97 \pm 0.11$ & $95.83 \pm 0.45$ \\
\hline Biscuit + TPE & $7.42 \pm 0.09$ & $57.83 \pm 0.13$ & $5.83 \pm 0.17$ & $9.92 \pm 0.12$ & $105.9 \pm 0.49$ \\
\hline Biscuit + GLE & $7.58 \pm 0.11$ & $58.00 \pm 0.14$ & $6.00 \pm 0.12$ & $9.66 \pm 0.12$ & $103.2 \pm 0.51$ \\
\hline Biscuit + BHA & $8.15 \pm 0.12$ & $58.66 \pm 0.15$ & $6.16 \pm 0.14$ & $9.52 \pm 0.13$ & $101.7 \pm 0.48$ \\
\hline Biscuit + TBHQ & $7.52 \pm 0.12$ & $58.16 \pm 0.16$ & $5.83 \pm 0.18$ & $9.97 \pm 0.12$ & $106.5 \pm 0.44$ \\
\hline
\end{tabular}

Values are mean \pm SD of six replicates ${ }^{*} P<0.001$.

The present study pointed out the physical parameters of biscuits were influenced by the different antioxidants added. This could be due to the interaction of antioxidants with various ingredients added to wheat flour during biscuit processing. The present study corroborated earlier reports on bakery products, Bassiouny et al. (1990), Hix et al. (1997), Bajaj et al. (2006) and Nanditha et al. (2009). The present study also indicates that the influence of bioactive compound in plant extracts on biscuit quality is more pronounced than that of synthetic ones. This may be due to interaction of components other than antioxidants (present in the natural antioxidant extracts) with other ingredients of biscuit formulation during processing of biscuits.

\section{Organoleptic properties of biscuits:}

The biscuits were subjected to sensory analysis by 10 trained panels. Evaluation was conducted on two occasions after baking, immediately and after 2 months of storage at room temperature. The biscuits prepared with CE and GLE were well accepted in terms of color, crumb color, texture and mouth feel and were comparable to control samples as well as BHA and TBHQ samples Table (4). The present study indicates that addition of natural antioxidants does not affect the sensory parameters of biscuits, which had shown the lowest acceptability. This could be due to the high ash content, which affects the gluten network formation in the biscuit dough, leading to poor texture. Addition of synthetic antioxidants, however, had good acceptability by sensory panelists. Similarly, Hix et al. (1997) conducted a study on physical and chemical attributes and consumer acceptance of sugar-snap cookies containing naturally occurring antioxidants. The objective of Hix et al. (1997) study was to test the shelf-life and other properties of sugar-snap cookies containing ascorbate, $\alpha$-tocopherol, sodium phytate and ferulic acid as viable replacements for BHA. The cookies were compared with regard to shelf-life, moisture content, width, stacking height, surface score, color and texture. Following storage at $60^{\circ} \mathrm{C}$, the Schaal oven test and gasliquid chromatographic analysis of headspace gases results indicated that ferulic acid and sodium phytate were suitable antioxidants for sugar-snap cookies. The test cookies were different than from BHA control cookies, Quilez et al. (2006). 
Table 4: Effect of various antioxidants and extracts on sensory characteristics of biscuits

\begin{tabular}{|l|c|c|c|c|c|c|c|}
\hline Biscuits & $\begin{array}{c}\text { Color } \\
(\mathbf{1 0})\end{array}$ & $\begin{array}{c}\text { Surface } \\
\text { character } \\
(\mathbf{1 0})\end{array}$ & $\begin{array}{c}\text { Crumb } \\
\text { color } \\
\mathbf{( 1 0 )}\end{array}$ & $\begin{array}{c}\text { Texture } \\
\mathbf{( 2 0 )}\end{array}$ & $\begin{array}{c}\text { Taste } \\
\mathbf{( 2 0 )}\end{array}$ & $\begin{array}{c}\text { Mouth } \\
\text { feel (10) }\end{array}$ & $\begin{array}{c}\text { Total } \\
\text { score } \\
(\mathbf{8 0})\end{array}$ \\
\hline Biscuit-control & $8.0 \pm 0.17$ & $8.5 \pm 0.13$ & $8.2 \pm 0.10$ & $16.0 \pm 0.15$ & $16.9 \pm 0.09$ & $8.1 \pm 0.10$ & $65.7 \pm 0.25$ \\
\hline Biscuit + CE & $8.0 \pm 0.12$ & $8.3 \pm 0.12$ & $6.7 \pm 0.12$ & $12.7 \pm 0.13$ & $17.0 \pm 0.07$ & $7.7 \pm 0.12$ & $60.3 \pm 0.28$ \\
\hline Biscuit + TPE & $7.6 \pm 0.09$ & $8.0 \pm 0.12$ & $7.9 \pm 0.10$ & $15.4 \pm 0.13$ & $16.0 \pm 0.10$ & $7.8 \pm 0.10$ & $62.6 \pm 0.38$ \\
\hline Biscuit + GLE & $8.3 \pm 0.12$ & $6.9 \pm 0.14$ & $7.5 \pm 0.13$ & $17.1 \pm 0.12$ & $17.3 \pm 0.08$ & $7.6 \pm 0.10$ & $64.6 \pm 0.29$ \\
\hline Biscuit + BHA & $7.6 \pm 0.13$ & $8.0 \pm 0.12$ & $7.7 \pm 0.10$ & $17.0 \pm 0.13$ & $17.6 \pm 0.23$ & $8.2 \pm 0.12$ & $66.0 \pm 0.31$ \\
\hline Biscuit+TBHQ & $7.8 \pm 0.12$ & $7.8 \pm 0.12$ & $7.4 \pm 0.11$ & $15.5 \pm 0.10$ & $16.9 \pm 0.10$ & $7.8 \pm 0.09$ & $63.2 \pm 0.32$ \\
\hline
\end{tabular}

Texture characteristics of biscuits:

Texture values of biscuits are shown in Table (5). The biscuits were stored, at 0 and 2 months and their texture were measured. The force required to break the control biscuit was around $1654 \mathrm{~g}$. It was observed that addition of BHA to biscuits did not affect grealty on the textural quality. Addition of TPE to biscuits slightly reduced the force required to break the biscuits. Addition of CE, GLE and TBHQ, however, significantly reduced the force required for breakage, indicating that biscuits had become fragile compared to control biscuits, probably due to interaction of antioxidants with flour components and the ingredients used in preparation. The texture analysis results concur with the score for texture during sensory analysis Table (5). Changes in texture of biscuits during storage for 2 months showed that there was not much change in the breaking strength of control and biscuits prepared with BHA. These results are agree with those of Bajaj et al. (2006) where biscuits were incorporated with mint extracts and compared with BHA for their textural attributes. The breaking strength of biscuits with TPE is comparable with BHA, indicating that biscuits containing TPE did not show significant changes in texture during the storage period. CE-enriched biscuits required slightly less force to break, but TBHQ biscuits were more fragile and affected the texture significantly.

Table 5: Changes in the textural quality of biscuits during storage (g) for 2 months

\begin{tabular}{|l|c|c|}
\hline Biscuit Sample & $\begin{array}{c}\text { Texture } \\
\mathbf{( 0 ~ m o n t h s )}\end{array}$ & $\begin{array}{c}\text { Texture } \\
\mathbf{( 2 ~ m o n t h s )}\end{array}$ \\
\hline Biscuit-control & $1654 \pm 6.15$ & $1536 \pm 9.89$ \\
\hline Biscuit + CE & $1220 \pm 9.17$ & $1178 \pm 7.28$ \\
\hline Biscuit + TPE & $1525 \pm 8.22$ & $1414 \pm 7.78$ \\
\hline Biscuit + GLE & $964 \pm 7.56$ & $888 \pm 5.87$ \\
\hline Biscuit + BHA & $1664 \pm 9.12$ & $1579 \pm 9.35$ \\
\hline Biscuit+TBHQ & $1029 \pm 6.38$ & $952 \pm 8.23$ \\
\hline
\end{tabular}

Values are mean \pm SD of six replicates $P<0.001$.

The present study clearly indicates that texture of biscuits was affected by incorporation of different antioxidants and extracts, except in the 
case of BHA. This could be due to interaction of these antioxidants in the tested extracts with the gluten network. Similar observations were reported by Bajaj et al. (2006). The effect of incorporation on the quality characteristics (texture and color) and acceptability of biscuits was also studied during the storage period by Bajaj et al. (2006). Park et al. (1997) also studied the effect of addition of fibre ingredients with different antioxidants on bread characteristics. The results indicated that the addition of those fibre ingredients increased dough absorption by about $25 \%$ and mixing time by about $50 \%$.

Effect of antioxidant addition on the oxidative stability of lipids in biscuit:

Peroxide value (PV) was estimated in all samples to determine the extent of peroxide formation due to oxidation of lipids (milli equivalents of $\mathrm{O}_{2}$ $\mathrm{kg}^{-1}$ of fat) during 2 months storage period as shown in Figure (1). Initially the PV in all samples was very low and increased during storage. After 15 days of storage the PV was increased in all samples, but in the case of GLEsample there was a sudden increase in PV from 0.0340 to 0.3747 . Thus, even though GLE-enriched sample showed high antioxidant activity, it was not effective in preventing oxidation of fat. Similarly, in the case of TPEsample there was an increase in PV to a much higher level than the other samples, from 0.0432 to 0.2739 . CE-enriched sample was found to be equally effective as BHA in preventing oxidation. After 2 months of storage, control sample showed the highest PV. Addition of antioxidants significantly reduced the oxidation of lipids. BHA was found to be more effective in preventing oxidation of fat during storage. TPE and CE samples were also found to be efficient in preventing oxidation and did not show much increase in PV. Addition of mint reduced peroxide formation in biscuits stored for 5 months, Lindenmeier \& Hofmann (2004).

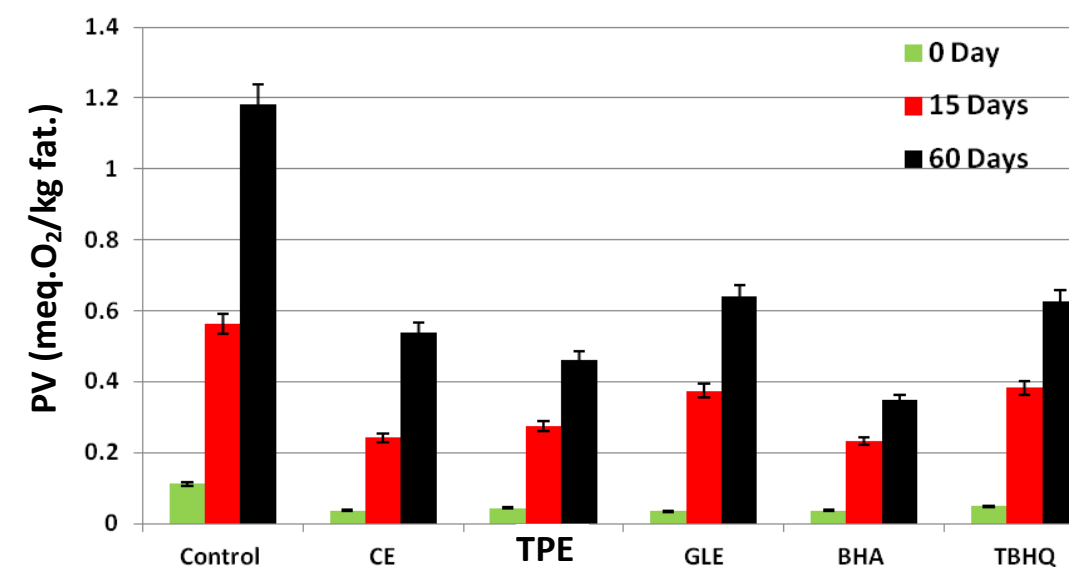

Figure 1: Changes in PV of lipids in biscuits enriched with different antioxidants after 2 months of storage 


\section{CONCLUSION}

In general, based on the result of retention of antioxidant activity during baking and storage and their ability to prevent lipid oxidation, extracts of carrot, grape leave extracts and turmeric powder were found to be suitable for use in biscuits as a natural antioxidants and results were comparable with $\mathrm{BHA}$ and $\mathrm{TBHQ}$.

\section{REFERENCES}

AACC (2000). Approved Methods of the American Association of Cereal Chemists. AACC, St Paul, MN, USA.

Anubala S., R. Sekar and K. Nagaiah (2014). Development and validation of an analytical method for the separation and determination of major bioactive curcuminoids in Curcuma longa rhizomes and herbal products using non-aqueous capillary electrophoresis. Talanta, 123: 10-17.

AOAC (1986). Methods of analysis, $7^{\text {th }}$ (ed.) Association of Official Agricultural Chemistry, St Paul MN, USA.

Bajaj, S., A. Urooj and P. Prabhasankar (2006). Effect of incorporation of mint on texture, colour and sensory parameters of biscuits. Int. J. Food Prop., 9: 691-700.

Bassiouny, S.S., F.R. Hassanien, F.A.E. Ali and S.M. El-Kayati (1990). Efficiency of antioxidants from natural sources in bakery products. Food Chem., 37: 297-305.

Chantaro, P., S. Devahastin and N. Chiewchan (2008). Production of antioxidant high dietary fiber powder from carrot peels. LWT - Food Sci. and Tech., 41: 1987-1994.

Dillard, C. J. and J. B. German (2000). Phytochemicals: nutraceuticals and human health. J. Sci. Food and Agri., 80: 1744-1756.

Dixit, Y. and A. Kar (2009). Antioxidative activity of some vegetable peels determined in vitro by inducing liver lipid peroxidation. Food Res. Int., 42: 1351-1354.

Fan, J.D., H. Lou, , W. Yu, D. Ren, B. Ma, and H. Ji (2004). Novel flavanol derivatives from grape seed. Tetrahedron Lett., 45: 3163-3166.

Ferreira, I.C.F.R. (2013). A review on antioxidants, prooxidants and related controversy: Natural and synthetic compounds, screening and analysis methodologies and future perspectives. Food and Chem. Toxicol., 51: 15-25.

Hiranvarachat B. and S. Devahastin (2014). Enhancement of microwaveassisted extraction via intermittent radiation: Extraction of carotenoids from carrot peels. J. Food Eng., 126: 17-26.

Hix, D.K., C.F. Klopfenstein and C.E. Walker (1997). Physical and chemical atttributes and consumer acceptance of sugar-snap cookies containing naturally occurring antioxidants. Cereal Chem., 74:281-283.

Jin, S., J.H. Hong, S.H. Jung and K.H. Cho (2011). Turmeric and laurel aqueous extracts exhibit in vitro anti-atherosclerotic activity and in vivo hypolipidemic effects in a zebra fish model. J. Med. Food, 14: 247-255. 
Krishnaswamy, K. (2008). Traditional Indian spices and their health significance. Asia. Pac. J. Clin. Nutr., $17: 265-268$.

$\mathrm{Li}$, L. and J. Zhong (2004). Effect of grape procyanidins on the apoptosis and mitochondrial transmembrane potential of thymus cells. Wei. ShengYan. Jiu., 33:191-194.

Liju V.B., K. Jeena and R. Kuttan (2013). Acute and subchronic toxicity as well as mutagenic evaluation of essential oil from turmeric (Curcuma longa L). Food and Chem. Toxiol., 53: 52-61.

Lindenmeier, M. and T. Hofmann (2004). Influence of baking conditions and precursor supplementation on the amounts of the antioxidant pronyl-Llysine in bakery products. J. Agric. Food Chem., 52:350-354.

Liu, F. and T.B. $\mathrm{Ng}$ (2000). Antioxidative and free radical scavenging activities of selected medicinal herbs. Life Sci., 66:725-737.

Madhavi, D.L., S.S. Deshpande and D.K. Salunkhe (1996). Food Antioxidants. Marcel Dekker, New York, USA.

Mildner, S.S., W.N. Zawirska, W. Obuehowski and M. Goslinski (2009). Evaluation of antioxidant activity of green tea extract and its effect on the biscuits lipid fraction oxidative stability. J. Sci. Food Agric., 89: 288- 298.

Monagas, M., B. Hernandez-Ledesma, C. Gomez-Cordoves and B. Bartalome (2006). Commercial dietary ingredients from Vitis vinifera $L$. leaves and grape skins: antioxidants and chemical characterization. J. Agr. Food. Chem., 54: 319-327.

Nanditha, B. R., B. S. Jenab and P. Pichan (2009). Influence of natural antioxidants and their carry-through property in biscuit processing. J Sci Food, 74: 362-370.

Pari, L. and Suresh, A. (2008). Effect of grape (Vitis vinifera L.) leaf extract on alcohol induced oxidative stress in rats. Food Chem. Toxicol., 46: 1627-1634.

Park, H., P.A. Seib and O.K. Chung (1994). Stabilities of several forms of vitamin $C$ during making and storing of pup-loaves of white pan bread. Cereal Chem., 71:412-417.

Park, H., P.A. Seib and O.K. Chung (1997). Fortifying bread with a mixture of wheat fiber and psyllium husk fiber plus three antioxidants. Cereal Chem., 74:207-211.

Park, J., J. Lee and W. Jun (2013). Radical scavenging and anti-obesity effects of various extracts from turmeric (Curcuma longa L.). J. Korean Soc. Food Sci. Nutr., 24: 1908-1914.

Pokorny, M. and P. Jan (1991). Natural antioxidants for food use. Trends in Food Sci. Technol., 223-226.

Pomrtanz, Y. (1988). Wheat Chemistry and Technology. American Association of Cereal Chemists, St Paul, MN, USA.

Prieto, P., M. Pineda and M. Aguilar (1999). Spectrophotometric quantitation of antioxidant capacity through the formation of a phosphomolybdenum complex: specific application to the determination of vitamin E. Anal. Biochem., 269:337-341. 
Quilez, J., J. A. G. Ruiz, Brufau and M. Rafecas (2006). Bakery products enriched with phytosterols, $\alpha$-tocopherol and $\beta$-carotene: sensory evaluation and chemical comparison with market products. Food Chem., 94:399-405.

Ranhotra, G.S., J.A. Gelroth, J. Langemeier and D.E. Rogers (1995). Stability and contribution of beta carotene added to whole wheat bread and crackers. Cereal Chem., 72:139-141.

Sai, M. and H. Rao (1999). Effect of emulsifiers, fat level and type on the rheological characteristics of biscuit dough and quality of biscuits. J. Sci. Food Agri., 79: 1223-1231.

Senedecor, G.W. and W.G. Cochran (1980). Statistical methods. $7^{\text {th }}$ the lowa Univ. Press, USA.

Sharma, M., P. Tripathi, V.P. Singh and Y.B. Tripathi (1995). Hepatoprotective and toxicological evaluation of hepatomed, an ayurvedic drug. Indian J. Exp. Biol., 33: 34-37.

Shyamala, B.N. and P. Jamuna (2010). Nutritional content and antioxidant properties of pulp waste from Daucus carota and Beta vulgaris. Malaysian J. Nutr., 16: 397-408.

Tripathi, Y.B., S. Chaurasia, E. Tripathi, A. Upadhyay and G.P. Dubey (1996). Bacopamonniera Linn. as an antioxidant: Mechanism of action. Indian J. Exp. Biol., 34: 523-526.

Vinson, J.A., Y. Hao, X. Su and L. Zubik (1998). Phenol antioxidant quantity and quality in foods: Vegetables. J. Agri. Food Chem., 46: 3630-3634.

Yu, L.L., K.K. Zhou and J. Parry (2005). Antioxidant properties of cold pressed black caraway, carrot, cranberry and hemp seed oils. Food Chem., 91:723-729.

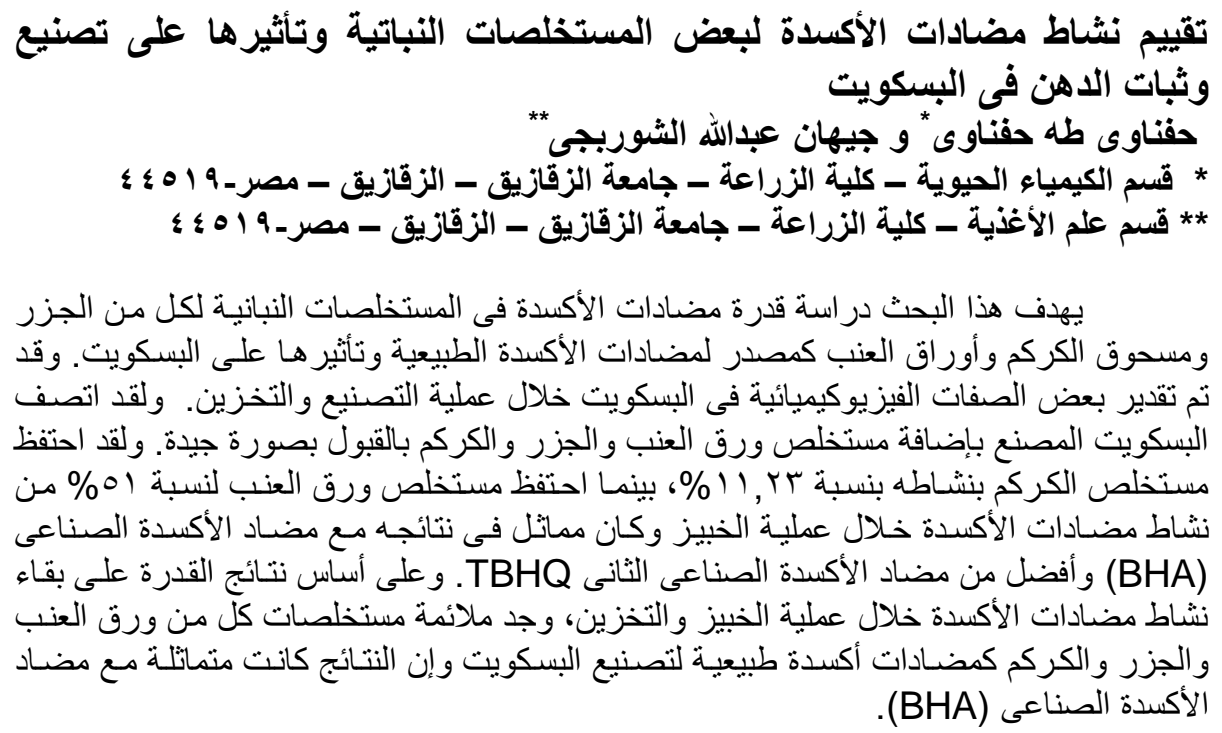

